\title{
EFFECTS OF SOIL STERILIZATION ON THE FORMATION AND FUNCTION OF TWO STRAINS OF PISOLITHUS TINCTORIUS ON EUCALYPTUS UROPHYLLA*)
}

\author{
NEULYS. AGGANGAN, BERNIEDEL \\ Biological and Environmental Sciences, Murdoch University, Perth, \\ Western Australia 6150 \\ NICKMALAJCZUK \\ CSIRO Division of Forestry, Private Bag P.O. Wembley, Western \\ Australia 6014 \\ REYNALDOE. DELACRUZ \\ BIOTECH, University of the Philippines at Los Ratios, College, \\ Laguna, Philippines 4031
}

\begin{abstract}
To examine the effects of soil microbial population on mycorrhizal development and function, Eucalyptus urophylla seedlings were inoculated with two Pisolithus tinctorius isolates and grown in sterile, partly sterile and non-sterile soil. The two isolates of Pisolithus were an effective isolate (H445) collected from under eucalypts in Australia and an isolate (H615) collected from under eucalypts in the Philippines. Soils used were infertile acid soils collected from field sites in Pangasinan, Luzon and Surigao, Mindanao.

In both soils, the Australian Pisolithus H445 improved the growth of E. urophylla seedlings more than Philippine isolate H615. The uninoculated seedlings exhibited stunted growth typical of P deficiency. Height at 8 weeks was significantly taller in sterile than in non-sterile soil. A significant interaction effect of inoculation and soil sterilization on height at harvest was observed only in Surigao soil.

Soil sterilization had a varied effect on mycorrhizal formation. In Pangasinan soil, root colonization by $\mathrm{H} 445$ was significantly greater in non-sterile soil than in sterile soil. Whereas in Surigao soil, root colonization was significantly reduced by $54 \%$ from partly sterile to non-sterile soil. On the other hand, H615 showed significant mycorrhizal colonization in non-sterile soil compared from those in partly sterile and sterile soils. The degree of infection did not necessarily correspond to growth promotion in $E$. urophylla seedlings.

These results indicate that the performance of the $\mathrm{H} 445$ was markedly affected by the microbial flora of the two soils. Thus, its potential use in the Philippines needs to be thoroughly tested in the field before its widespread use in any inoculation program.
\end{abstract}

Key words: Mycorrhizas/Soil sterilization/Pisoto/ws tinctorius/Eucalyptus urophylla.

\footnotetext{
*)Paper presented at the Second Symposium on Biology and Biotechnology of Mycorrhizae and Third Asian

Conference in Mycorrhizae (ACOM HI), 19-21 April 1994, Yogyakarta, Indonesia.
} 


\section{INTRODUCTION}

Eucalypts are important reforestation species grown in the Philippines to provide raw materials for the pulp and lumber industries. Their fast growth and adaptability to low nutrient soils might be dependent on the presence of symbiotic mycorrhizal associations. For example, previous inoculation work carried out in the Philippines on Pisolithus and eucalypts indicate growth enhancement with a Pisolithus isolate collected from under Pinus in the Philippines (De la Cruz et al. 1990, 1991).

Pisolithus species have been shown to increase survival and growth of a wide range of tree species such as oaks, pines and eucalypts. In the tropics, Lee Su See et al. (1994) found that a Pisolithus isolate colonized the roots and subsequently improved the growth of two dipterocarp seedlings grown in the nursery. Recent work conducted by Burgess et al. (1994a) found that growth stimulation of E. grandis seedlings varied greatly among 20 isolates of Pisolithus. An isolate (H445) collected from under eucalypts was one of the best growth promoters. This same isolate has also been reported to dramatically increase the growth of E. globulus and E. diversi-color in other studies (Burgess et al. 1993). However, not all isolates are beneficial to plant growth. For example, Tonkin et al. (1988) observed severe root reduction and retarded shoot growth of $E$. marginata when inoculated with certain Pisolithus isolates in aseptic condition. One factor influencing the response of eucalypts to inoculation with Pisolithus is the host from which the isolate was isolated. Pine isolates of Pisolithus, for example, have been shown to form poor associations with eucalypts (Malajczuk et al. 1982, 1990; Burgess et al. 1994a).

In the development of an inoculation program for nurseries in the Philippines, it is essential to introduce compatible ectomycorrhizal isolates that can improve the growth of eucalypts. Isolate H445 presents a possible candidate for such introduction. Introduction of Pisolithus isolates into the Philippines from Australia requires a thorough testing of the behaviour of these fungi on roots of eucalypt seedlings growing in soil collected from field sites in the Philippines. In addition, it is necessary to compare the performance of introduced Australian isolates with local Philippine Pisolithus isolates.

The glasshouse screening experiments conducted, so far, for Pisolithus and eucalypts have used pasteurized soil (Burgess et al. 1993, 1994a). It is important to understand factors that affect inoculum survival and persistence of fungi on eucalypt roots in the field. Predicting the effectiveness and competitiveness of introduced ectomycorrhizal fungi in the field, and comparison with previous glasshouse experiments, requires preliminary testing of the fungi in the presence or in the absence of native soil microflora. In a sterile condition, all the native microorganisms 
are eliminated by sterilization, thus leaving the introduced mycorrhizal fungi to function freely without interference from other microbes. In non-sterile soil, on the other hand, the introduced fungi must compete with other microorganisms in order to survive and function. This would represent conditions similar to those in the field. It is also possible that partial sterilization such as incorporation of a small amount of non-sterile soil to a fumigated one, can stimulate an isolate to develop and absorb more nutrients.

In this paper, the effectiveness of an Australian (H445) and a Philippine Pisolithus isolate (H615) on the formation of ectomycorrhizas and growth stimulation of $E$. urophylla seedlings was compared. Plants were grown in soils collected in the Philippines and subjected to three sterilization treatments (non-sterile, partly sterile and sterile soil).

\section{MATERIALS AND METHODS}

\section{Seed Germination and Mycorrhizal Synthesis}

Seeds of E. urophylla (seedlot \# 18094 from Mt. Egon, Flores Island, Indonesia), obtained from CSIRO Australian Tree Seed Centre (Canberra, Australia), were aseptically germinated on agar plates. Seeds were washed with $70 \%$ ethanol containing Tween 20 for one minute, surface sterilized with $10 \%$ sodium hypochlorite for 5 minutes and washed three times with sterile water.

Two isolates of Pisolithus were selected: a) H445 - an isolate provided by CSIRO Division of Forestry, collected under E. marginata in Western Australia and which has been shown to stimulate the growth of eucalypts in field trials, and b) H615 - collected under $E$. camaldulensis in the Philippines but probably associated with Pinus (Burgess et al. 1994b).

Ectomycorrhizas were synthesized aseptically in petri dishes by transferring 7 day-old germinants onto the surface of 10-day old hyphal mats growing on Modified Melin Norkrans medium (Marx 1969) with low glucose concentration (1.75 g/L) for two weeks (Malajczuk et al. 1990). Plates were incubated in a growth room set at $12 \mathrm{hrs}$ photoperiod and temperature of $25^{\circ} \mathrm{C}$. At 10 days they were transplanted into undrained pots containing $2 \mathrm{~kg}$ soil. The surface of each pot was covered with aluminium foil with four holes where the seedlings were inserted. The foil reduced water loss from the soil and minimized spore contamination. After four weeks, the seedlings were thinned to two plants per pot. 


\section{Soil Treatments}

Soils (0- 15cm depth) were collected at sites in: a) Labrador, Pangasinan, Luzon and b) in Bislig, Surigao Sur, Mindanao, referred to in figures as Pangasinan and Surigao soil, respectively. Both sites are grasslands which previously were monsoon forests dominated with dipterocarps. The Pangasinan soil has a $\mathrm{pH}$ of 4.1 (1:1 soil, $0.005 \mathrm{M}$ $\mathrm{CaCl}$ ), $2.02 \%$ organic matter (Walkey-Black Method), $0.11 \%$ Total N (Modified Kjeldahl Method), and 0.84 ppm available P (Bray No. 2) while the Surigao soil has a pH of 5.9, $2.48 \%$ organic matter, $0.06 \%$ Total $\mathrm{N}$ and $0.21 \mathrm{ppm}$ available $\mathrm{P}$. Textural class of the two soils is silt loam. The soils were air dried, pulverized and passed through a $2 \mathrm{~mm}$ screen. Two kg dry soil were dispensed into plastic pots with polyethylene bag liners.

Soil treatments were: sterile, partly sterile and non-sterile. Pots designated as sterile and partly sterile were fumigated with methyl bromide (one canister per $\mathrm{m}^{3}$ soil) in a fumigation chamber for 3 days. The non-sterile designated pots were left unfumigated. The partly sterile soil treatment was prepared by mixing $1 \%$ unfumigated soil with $99 \%$ methyl bromide, fumigated soil.

\section{Addition of Fertilizer}

One week after fumigation, all pots received the following basal nutrients (per $\mathrm{kg}$ soil): $16 \mathrm{mg} \mathrm{Ca}\left(\mathrm{H}_{2} \mathrm{PO}_{4}\right)_{2} \cdot \mathrm{H}_{2} \mathrm{O}, 270 \mathrm{mg} \mathrm{NH} \mathrm{NO}_{3}, 233 \mathrm{mg} \mathrm{K}_{2} \mathrm{SO}_{4}, 71.3 \mathrm{mg} \mathrm{CaCl}, 21.4 \mathrm{mg}$ $\mathrm{Mg} \mathrm{SO}_{4} .7 \mathrm{H}_{2} \mathrm{O}, 10 \mathrm{mg} \mathrm{ZnSO} \cdot 7 \mathrm{H}_{2} \mathrm{O}, 5 \mathrm{mg} \mathrm{CuSO} \cdot 5 \mathrm{H}_{2} \mathrm{O}, 0.36 \mathrm{mg} \mathrm{CoSO} \cdot 7 \mathrm{H}_{2} \mathrm{O}, 0.7 \mathrm{mg}$ $\mathrm{H}_{3} \mathrm{BO}_{3}$ and $1.62 \mathrm{mg} \mathrm{Na} 2 \mathrm{MoO}_{4} \cdot 2 \mathrm{H}_{2} \mathrm{O}$. Manganese and iron were not included because the soils had high concentration of these elements (Dell, unpublished). The nutrient solutions were added evenly on the soil surface after sterilization. The soil was mixed thoroughly and watered to $80 \%$ field capacity and incubated in benches inside a screenhouse for five days prior to planting.

\section{Seedling Maintenance and Growth Monitoring}

Two weeks after transplanting, $2.5 \mathrm{ml}$ nitrogen solution $\left(54 \mathrm{~g} \mathrm{NH}_{4} \mathrm{NO}_{3} / \mathrm{L} \mathrm{H}_{2} \mathrm{O}\right)$ $\operatorname{pot}^{-1}$ week $^{-1}$ was added. The same rate was added for the next two weeks after which the rate of nitrogen was increased to $5 \mathrm{ml} \mathrm{pot}^{-1}$ week $^{-1}$ for a period of 7 weeks. All pots were watered to field capacity by weight when necessary. Height was monitored twice a month. 
Effects of soil sterilization - Nelly S. Aggangan et al.

\section{Harvest and Mycorrhizal Assessment}

After 12 weeks, the seedlings were harvested. Shoots were cut $1 \mathrm{~cm}$ above the soil surface and the root systems were gently washed under running water. Fine roots (diameter less than $0.5 \mathrm{~mm}$ ) were separated from the coarse roots, blotted dry in between paper towels and cut into $1 \mathrm{~cm}$ lengths. Fine root samples of $0.2 \mathrm{~g}$ fresh weight were further chopped into 1-2 mm lengths and were fixed in $70 \%$ ethanol for counting mycorrhizal root infection. Fine roots were cleared and stained as described by Phillips and Hayman (1970). Stained roots were spread evenly over a petri dish and were examined under a stereomicroscope. Ten randomly selected fields of view were chosen and all roots crossing a hair-line were examined for the presence or absence of infection. Fully colonized root tips were scored as mycorrhizal.

\section{Experimental Design and Statistical Analysis}

The experiment was conducted in a screenhouse at BIOTECH, UP Los Banos, Philippines following a two factor (fungi and soil treatment) factorial in Randomized Complete Block Design (RCBD) with three replicates. Pots were rearranged in benches once a week. Within each soil type, all data collected were analyzed statistically using two way ANOVA. Treatment means were compared using Duncan's Multiple Range Test at $\mathrm{P}<0.05$.

\section{RESULTS}

\section{Plant Growth}

In Pangasinan soil, inoculation (as Factor A) significantly $(\mathrm{P}<0.01)$ affected heights at 6, 8,10 and 12 weeks (at harvest) after planting, and dry matter yields (shoot, root, fine root, coarse root and total biomass). Generally, the Australian Pisolithus H445 was more effective in increasing height growth of E. urophylla seedlings from 6 weeks to 12 weeks after planting, dry matter yields and phosphorus uptake (data not shown) than the Philippine isolate H615. Inoculation with the Australian isolate increased $(\mathrm{P}<0.05)$ height at 6 weeks until 12 weeks (harvest) after planting. H615 significantly increased seedling heights from 6 weeks to 10 weeks after planting compared with the uninoculated plants but significantly shorter than those inoculated with H445. At harvest (12 weeks) however, height of seedlings inoculated with the Philippine isolate was not significant compared with the uninoculated counterpart. Likewise, soil sterilization (as Factor B) significantly affected 
height at 6 weeks $(\mathrm{P}<0.01)$ and at 8 weeks $(\mathrm{P}<0.05)$ and fine root dry matter yield $(\mathrm{P}<$ $0.05)$. Height at 6 and 8 weeks after planting and fine root dry weight obtained in sterile soil were significantly higher than in non-sterile soil. Heights and fine root dry weight in partly sterile soil were intermediate and these were not significant compared with those in sterile soil as well as those in non-sterile soil. There was no significant interaction effects of inoculation and soil sterilization on any of the periodic height measurements (Fig. 1A). Height at harvest due to inoculation with $\mathrm{H} 445$ was increased by 4x, 5x and 8x in sterile, partly sterile and in non-sterile soil, respectively, relative to the uninoculated seedlings. On the other hand, H615 increased seedling heights by $1.2 \mathrm{x}, 2 \mathrm{x}$ and $3 \mathrm{x}$ in the same soil treatment order. Although the mean height of $\mathrm{H} 445$ plants were two times taller than those of H615, there was no significant differences among treatments. The uninoculated seedlings had the shortest height in all the three soil treatments. Height of uninoculated plants was reduced by 2 folds while total dry weight (data not presented) by 10 folds from sterile to non-sterile soils. Whereas, the inoculated seedlings did not differ much irrespective of soil treatment. Shoot dry weight (data not presented) showed similar trends to plant height. A significant interaction effect was observed only on fine root dry weight. Fine root dry weight was dramatically increased $(\mathrm{P}<0.05)$ by $\mathrm{H} 445$ in sterile (Fig. 2A) compared with H615 and uninoculated treatments. Fine root dry weight was greater $(\mathrm{P}<0.05)$ in sterile than in non-sterile soil.

In Surigao soil, inoculation (as Factor A) significantly affected height at 6 to 12 weeks after planting, coarse root dry weight, root $\mathrm{P}$ concentration and uptake and shoot $\mathrm{P}$ uptake. H445 and H615 inoculated seedlings were of similar height which was significant compared with height of the uninoculated ones from 6 to 10 weeks after planting. At harvest, H445 inoculated plants were significantly taller than those inoculated with H615 and the uninoculated ones. Although, height at harvest, coarse root dry weight and root $\mathrm{P}$ concentration obtained by $\mathrm{H} 615$ inoculated plants were twice those of uninoculated counterpart, the differences were not statistically significant. Soil sterilization (Factor B) significantly affected height at 8 weeks and shoot $\mathrm{P}$ concentration. Height in sterile soil was significantly taller than in partly sterile and non-sterile. The latter soil treatments (partly sterile and non-sterile soil) yielded similar height growth response. Shoot $\mathrm{P}$ concentration in partly sterile soil was significantly higher than in non-sterile soil. Unlike in Pangasinan soil, there was a significant interaction effect of inoculation and soil treatment. In sterile, H445 was consistent in promoting a significant increase in height $(\mathrm{P}<0.01)$ from 6 weeks until harvest (Fig. 1B) compared with the uninoculated seedlings. Two way analysis revealed that height growth obtained by seedlings inoculated with $\mathrm{H} 445$ in sterile soil was significant compared with those inoculated with H615 and the uninoculated ones. In partly sterile soil, height obtained by $\mathrm{H} 445$ 
Effects of soil sterilization - Nelly S. Aggangan et al.
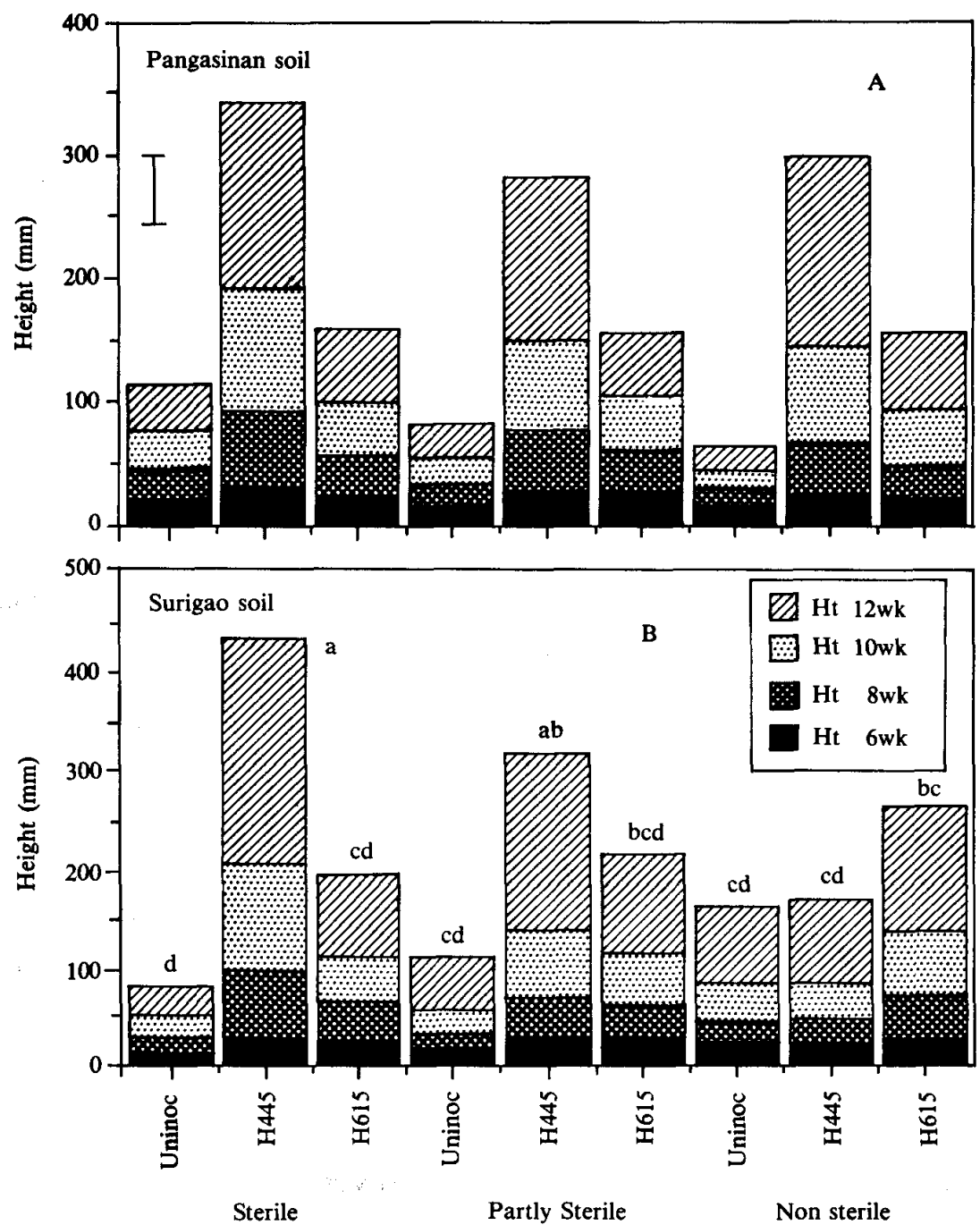

SOIL TREATMENTS

Figure 1. Effects of mycorrhizal inoculation on the accumulated height growth of E. urophylla seedlings grown in Pangasinan (A) and Surigao (B) soils subjected to three sterilization treatments. Letters represent results of Duncan's Multiple Range Test after two way ANOVA on height at 12 weeks on each soil treatment. $\mathrm{LSD}$ bar $=56$. 
inoculated seedlings was significantly taller than the uninoculated seedlings but not significant as compared with those inoculated with H615. In non-sterile soil, height differences between the inoculated and uninoculated seedlings was not significant. H615 inoculation gave intermediate height and shoot dry weight in sterile and in partly sterile soil which were not statistically different from the uninoculated seedlings. Unlike seedlings grown in Pangasinan soil, there was no significant interaction effect of inoculation and soil sterilization on fine root dry weight (Fig. 2B). However, plants had much larger shoot and root systems in the Surigao than in the Pangasinan soil.

\section{Mycorrhizal Development}

In Pangasinan soil, there was a significant difference between the three inoculation treatments and soil sterilization significantly affected mycorrhizal development. Mycorrhizal infection by H445 was significantly higher (41\%) than H615 (21\%). The uninoculated seedlings had $7 \%$ infection. Mycorrhizal infection in non-sterile soil was significantly higher $(30 \%)$ than in sterile soil $(18 \%)$. Root colonization in partly sterile soil was intermediate which was not significant compared with those obtained in sterile or in non-sterile soils. Two way analysis indicates that in sterile and non-sterile soils, H445 and H615 had similar infection levels (Fig. 2C). However, in partly sterile soil, H445 had greater $(\mathrm{P}<0.01)$ root colonization than $\mathrm{H615}$. Root colonization by $\mathrm{H} 445$ was significantly higher in non-sterile than in sterile soil but not significant compared with those in sterile and in non-sterile soils. Uninoculated seedlings had low levels (not more than $11 \%$ ) of infection in the two soils (Fig. 2C).

In Surigao soil, mycorrhizal development formed by H445 and H615 (as Factor A) was not significantly different from each other but significant compared with the uninoculated treatment. Root colonization was significantly higher in non-sterile and in partly sterile soils than in sterile soil. There was a significant interaction effect of inoculation and soil sterilization treatments. In non-sterile soil, H615 formed higher $(\mathrm{P}<0.05)$ infection compared with H445 (Fig. 2D). Greatest mycorrhizal formation by H445 was observed in partly sterile soil which was reduced $(\mathrm{P}<0.05)$ in sterile and in non-sterile soils. Percent mycorrhizal infection by $\mathrm{H} 445$ in non-sterile soil was similar to that of uninoculated plants grown in either of the three soil treatments. Root colonization by $\mathrm{H} 615$ was higher $(\mathrm{P}<0.01)$ in non-sterile $(65 \%)$ than in partly sterile soil $(34 \%)$. Infection in sterile soil was intermediate and not significantly different to percent mycorrhizal infections observed in non-sterile and in partly sterile soils. Correlation analyses revealed a low relationship $\left(r^{2}=0.6\right)$ between percent mycorrhizal infection and height or shoot and fine root dry weight. 
Effects of soil sterilization - Nelly S. Aggangan et al.
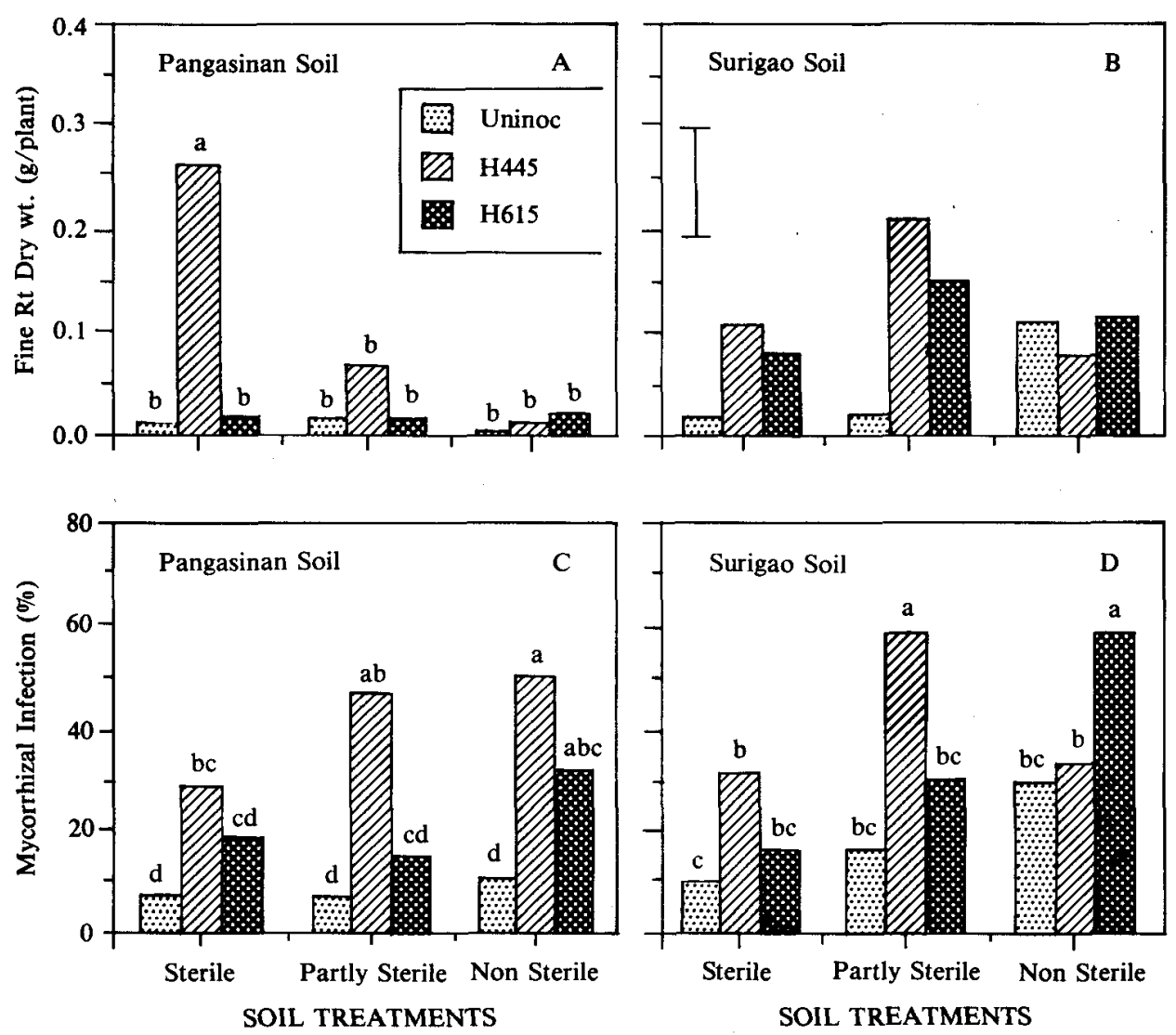

Figure 2. Fine root dry matter weight (A and B) and mycorrhizal infection (C and D) of E. urophylla seedlings inoculated with two Pisolithus isolates grown on sterile, partly sterile and non-sterile acid soils. Letters represent results of Duncan's Multiple Range Test after two way ANOVA on each soil. $\mathrm{LSD}$ bar $=0.116$. 


\section{DISCUSSION}

Growth of E. urophylla seedlings in the two Philippine soils was stimulated by inoculation with two isolates of Pisolithus. Growth of plants inoculated with the Australian eucalypt isolate, H445, was enhanced more than those inoculated with the Philippine isolate, H615. Previously, H615 was classified as a pine isolate (Burgess et al. 1994b) on the basis of polypeptide patterns identified by ID SDS-PAGE.

The effectiveness of a pine Pisolithus isolate in promoting growth of eucalypts has been demonstrated in field trials (De La Cruz et al. 1990, 1991). Potentially, the introduction of Australian isolates in any nursery inoculation programs in the Philippines would provide an advantage for growth promotion of eucalypts. It remains to be determined whether these specific eucalypt isolates would persist and outperform the indigenous pine Pisolithus isolates in the field. It is interesting to note that Garbaye et al. (1988) observed the replacement of an introduced pine isolate (Marx strain 270), by an indigenous Scleroderma species within 2 years after outplanting.

In this experiment, mycorrhizal root development was markedly affected by sterilization treatment in one Philippine soil (Surigao). Mycorrhizal infection by $\mathrm{H} 445$ was reduced by $54 \%$ in non-sterile soil. In contrast, H615, was unaffected by soil sterilization treatments. This would suggest a possible role of soil microflora in affecting the infection process. Several studies have suggested that soil microflora play an important role in influencing the inoculation process of seedling roots by mycorrhizal fungi (Garbaye and Bowen 1987; Marx et al. 1982, 1984). Such effect may be inhibitory or stimulatory to mycorrhizal formation (Bowen and Theodorou 1979; Garbaye and Bowen 1989; Fitter and Garbaye 1994).

It would appear that the introduction of new strains of ectomycorrhizal fungi from Australia and screening of endemic strains requires a thorough testing of the performance in a range of soils. It is anticipated that no single species would be appropriate for all soil types in the Philippines and the introduction should include a wide range of physiologically distinct species. Introduced ectomycorrhizal fungi should be able to survive and tolerate ecological variation within a site and progressively colonize the new roots after outplanting (Garbaye 1982). Most importantly, the introduced fungi must enhance host performance to a greater degree than the native fungi (Danielson 1988). Competitiveness or persistence of the association would depend on three factors: the host, mycorrhizal fungus and soil microbes wherein each factor is subject to environmental influences. Further work is required to examine the influence of the composition of the microbial population on ectomycorrhizal formation on a range of Philippines soil. 


\section{ACKNOWLEDGEMENTS}

This work was supported by the Australian International Development Bureau and the Australian Center for Agricultural Research while Dr. Nelly S. Aggangan was doing her postgraduate degree.

\section{REFERENCES}

BURGESS, T., N. MALAJCZUK and B. DELL. 1994a. Variation in mycorrhizal development and growth stimulation of 20 Pisolithus isolates inoculated onto Eucalyptus grandis W. Hill ex Maiden. New Phytol (in press).

BURGESS, T., N. MALAJCZUK and B. DELL. 1994b. Variation in Pisolithus based on basidiocarp and basidiospore morphology, culture characteristic and polypeptide analysis using ID-SDS PAGE (in press).

BURGESS, T., N. MALAJCZUK and T.S. GROVE. 1993. The ability of 16 ectomycorrhizal fungi to increase the growth and phosphorus uptake of Eucalyptus globutus Labill and E. diversicolor F. Muell. Plant and Soil 153: 155-164.

BOWEN, G.D. and C. THEODOROU. 1979. Interactions between bacteria and ectomycorrhizal fungi. Soil. Biol. and Biochem. 11: 119-126.

DANIELSON, R.M. 1988. Mycorrhizae in Forestry: the state-of-the-art in land reclamation. In Canadian Workshop on Mycorrhizae in Forestry, 1 -4 May 1988, Universite Laval, Ste-Foy, Que. Edited by M. Lalonde and Y. Piche. Universite Laval, Ste-Foy, Que. p. 39-41.

DELACRUZ, R.E., N.S. AGGANGAN, J.T. ZARATE and R.P. YECYEC. 1991. Improved reforestation technologies in the Philippines. PCARRD Book Series 121: 65-78.

DE LA CRUZ, R.E., E.B. LORILA and N.S. AGGANGAN. 1990. Ectomycorrhizal tablets for Eucalypthus species. In Fast growing Tress and Nitrogen Fixing Tress. Eds. D Werner and P muller, Gustav Fisher Verlag, Stuttgart, New York. p. 371.

FITTER, A.H. and GARBAYE, J. 1994. Interactions between mycorrhizal fungi and other soil arganisms. Plant and Soil 159: $123-132$.

GARBAYE, J. 1982. Quelques aspects de la competitive des souches ectomycorhiziennes. In Les Mycorhizes, Panic Integrante de la Plante: Biologic et Perspectives d'Utilisation. Eds. S Gianinazzi, V Gianinazzi-Pearson and A Trouvelot. pp. 303-312. Proceedings of a seminar, 5-6May 1982 atm Dijon, France, les Colloques de FINRA, no.13.

GARBAYE, J. and G.D. BOWEN. 1987. Effect of Different microflora on the success of ectomycorrhizal inoculation of Pinus radiata. Can.J.For. Res. 17: 941-943.

GARBAYE, J. and G.D. BOWEN. 1989. Stimulation of ectomycorrhizal infection of Pinus radiata by some microorganisms associated with the mantle of ectomycorrhizas. New Phytol. 112: 383-386.

GARBAYE, J., J.C. DELWAULLE and D. DIANGANA. 1988. Growth response of eucalypts in the Congo to ectomycorrhizal inoculation. Forest Ecology and Management 24: 151-157.

LEE Su SEE, F. LAPEYRIE and MOHD. YAZID ZANIP. 1994. Techniques for controlled ectomycorrhizal inoculation of dipterocarp seedlings and cuttings. In Programs and Abstract Third Asian Conference on Mycorrhizae, 19-21 April 1994, Yogyakarta, Indonesia, p. 4-6. 
MALAJCZUK, N., F. LAPEYRIEand J. GARBAYE. 1990. Infectivity of pine and eucalypt isolates of Pisolithus tinctorius on roots of Eucalyptus urophylla in vitro. New Phytologist 114: 627-631.

MALAJCZUK, N, R. MOLINAand J. TRAPPE. 1982. Ectomycorrhizal formation in Eucalyptus. I. Pure culture synthesis, host specificty and mycorrhizal compatility with Pinus radiata, New Phytol. 91: 467-482.

MARX, D.X. 1969. The influence of ectotropic mycorrhizal fungi on the resistance of pine roots to pathogenic infection. I. Antagonism of mycorrhizal fungi to root pathogenic fungi and soil bacteria. Phytopathology 59: 153-163.

MARX, D.H., J.L RUEHLE, D.S. KENNY, C.E. CORDELL, J.W. RIFFLE, R.J. MOLINA, W.H. PAWUK, S. NAVRATIL, R.W. TINUS and O.C. GOODWIN. 1982. Commercial vegetative inoculum of Pisolithus tinctorius and inoculation techniques for development of ectomycorrhizae on container-grown tree seedlings For. Sci. 28(2): 373-403.

MARX, D.H., C.E. CORDELL, D.S. KENNY, J.G. MEXAL, J.D. ARTHMAN, J.W. RIFFLE and J.W. MOLINA. 1984. Commercial vegetative inoculum of Pisolithus tinctorius and inoculation techniques for development of ectomycorrhizae on bare-root tree seedlings. For. Sci. Monogr. No. 25.

PHILLIPS, J.M. and D.S. HAYMAN. 1970. Improved procedures for clearing roots and staining parasitic and vesicular-arbuscular mycorrhizal fungi for rapid assessment of infection. Trans. Brit. Mycol. Soc. 55: 158-160.

TONKIN, N.C., N. MALAJCZUK and J.A. McCoMB. 1988. Ectomycorrhizal formation by micro-propagated clones of Eucalyptus marginata inoculated with isolates of Pisolithus tinctorius. New Phytologist 111: 209-214. 